\title{
Unmasking Sensory Defects of Olive Oils Flavored with Basil and Oregano Using an Electronic Tongue-Chemometric Tool
}

\author{
Marta Bobiano $^{1}$ - Nuno Rodrigues ${ }^{1} \cdot$ Marta Madureira $^{1} \cdot$ Luís G. Dias $^{1} \cdot$ Ana C. A. Veloso $^{2,3}$. \\ José A. Pereira ${ }^{1} \cdot$ António M. Peres $^{1,4}$ (i)
}

Received: 17 April 2019 / Revised: 17 May 2019 / Accepted: 20 May 2019

(C) 2019 AOCS

\begin{abstract}
Olive oil price and consumers' preference depend on the commercial grade classification that can decrease if any sensory defect is perceived leading to an economic loss. Enriched oils, obtained by incorporating dried aromatic herbs, spices, or essential oils, which is a common practice in the Mediterranean region, are commercially available. This practice may conceal the fraudulent purpose of masking the perception of sensory defects. The detection of this type of fraud is a difficult task, requiring sensory analysis. Thus, in this study, extra-virgin and lampante olive oils, the latter classification being due to the perception of an intense winey-vinegary defect, were deliberately enriched with different amounts of basil-dried herbs and oregano-dried herbs. Sensory analysis showed that, depending on the aromatic herb and on the added amount $(0.011-0.110 \mathrm{~g}$ herb per $\mathrm{kg}$ oil), the defect intensity could be masked leading to an erroneous classification of flavored lampante oils as flavored virgin oils. In contrast, the electronic tongue-chemometric approach could unmask the defect in flavored oils (predictive sensitivities: 70-78\%) and semiquantitatively discriminate flavored oils according to the added levels of basil or oregano (predictive sensitivities:
\end{abstract}

António M. Peres

peres@ipb.pt

1 Centro de Investigação de Montanha (CIMO), ESA, Instituto Politécnico de Bragança, Campus Santa Apolónia, 5300-253, Bragança, Portugal

2 Instituto Politécnico de Coimbra, ISEC, DEQB, Rua Pedro Nunes, Quinta da Nora, 3030-199, Coimbra, Portugal

3 CEB - Centre of Biological Engineering, University of Minho, Campus de Gualtar, 4710-057, Braga, Portugal

4 Laboratory of Separation and Reaction Engineering-Laboratory of Catalysis and Materials (LSRE-LCM), ESA, Instituto Politécnico de Bragança, Campus Santa Apolónia, 5300-253, Bragança, Portugal
93-100\%). The electronic tongue approach showed satisfactory unmasking performance when compared with the sensory panel, and so, its future application as a quality control tastesensor device for disclosing olive oil sensory defects masked by the incorporation of flavoring agents may be forseen.

Keywords Olive oil · Physicochemical analysis · Sensory analysis - Aromatic herbs flavoring - Electronic tongue . Sensory defect detection

J Am Oil Chem Soc (2019) 96: 751-760.

\section{Introduction}

Olive oil plays a key role in the Mediterranean diet, providing the intake of several bioactive compounds with recognized nutritional and healthy effects. These effects may even be enhanced by the consumption of enriched olive oils (EnVOO) (Rubió et al., 2012). The production of En-VOO is aimed to increase the oxidative stability (OS), and thus the oil shelf-life as well as to enhance oil taste and aroma, contributing to mask the intensity of some attributes, like bitterness, which although being considered a positive sensation from a sensory classification point of view, is not very appreciated by the consumers of some geographical regions (Moldão-Martins et al., 2004). Different nature-based matrices have been used to obtain En-VOO, including, aromatic herbs and spices (e.g., basil, caraway, chili peppers and red pepper, garlic, lemon and lemon peels, laurel, lavender, menthe, orange peels, oregano, rosemary, sage, and thyme), either through incorporation techniques (Ayadi et al., 2009; Gambacorta et al., 2007; Sousa et al., 2015) or by the addition of purified extracts or essential oils (Assami et al., 2016; 
Baiano et al., 2016; Caponio et al., 2016; Clodoveo et al., 2016; Khemakhem et al., 2015; Sacchi et al., 2017).

Olive oil enrichment could also comprise a fraudulent practice. Indeed, the addition of aromatic herbs and spices may contribute to mask the sensory perception of organoleptic defects that when perceived leads to a great decrease of the olive oil commercial value, and so reducing the economic revenue of the olive oil producers. Indeed, even if from a physicochemical point of view an olive oil may be classified as extravirgin olive oil (EVOO), its grade may decrease to virgin olive oil (VOO) if an organoleptic defect is perceived with an intensity up to 3.5 in a $0-10$ scale intensity range or to a lampante olive oil (LOO, which cannot be commercialized) if the perceived defect intensity is greater than 3.5 (Commission Delegated Regulation [EU] 2015/1830, 2015). The implementation of this fraudulent practice may allow the commercial disposal of lower-quality olive oils.

Thus, the development of practical, fast, and accurate strategies that could be used to discriminate flavored from unflavored olive oils, of different quality grades, is of utmost relevance and could allow unmasking possible frauds related to the deliberated enrichment of sensory defected olive oils aiming its commercialization as high quality and more expensive olive oils. Officially, olive oils sensory profile must be established by a trained taste panel (Commission Delegated Regulation [EU] 2015/1830, 2015), which poses several drawbacks, namely due to the scarcity of official panels, lack of reference standards, and a low number of analyses per day (Sinelli et al., 2010). Alternatively, potentiometric and voltammetric electronic tongues (E-tongues) have been successfully used to evaluate positive sensory attributes (e.g., bitter, green, and/or fruity sensations) and organoleptic defects (e.g., rancid, winey-vinegary, musty, fusty, zapateria, butyric, and putrid sensations) of olive oils and table olives as well as to unmask the deliberated addition of rancid or winey-vinegary olive oil to EVOO (Harzalli et al., 2018; Rodrigues et al., 2019; Veloso et al., 2016, 2018). This work aims, for the first time, to evaluate the possibility of using a potentiometric E-tongue, comprising lipid-polymeric sensor membranes, in combination with chemometric tools to discriminate EVOO or LOO, flavored or not, with basil or oregano. The main goal is to use the E-tongue to unmask sensory defected olive oils after their flavor enrichment by the addition of natural aromatic herbs, which is a typical practice in the Mediterranean countries.

\section{Materials and Methods}

\section{Olive Oil Samples and Flavoring Procedure}

Cv. Arbequina olive oils from two different production lots (lot \#1 and lot \#2) were obtained from a local olive mill
(Olimontes, Macedo de Cavaleiros, Portugal). An initial quality evaluation (data not shown) was performed showing that, from a physicochemical point of view, the oils from both lots were EVOO, fulfilling the legal thresholds established by the European Commission (EC) regulations (Commission Delegated Regulation [EU] 2015/1830, 2015; Sacchi et al., 2017). From a sensory point of view, and according to the sensory analysis performed by eight trained panelists of the Agricultural School of the Polytechnic Institute of Bragança, the oils from lot \#1 and lot \#2 had a fruity intensity sensation greater than 0 fulfilling the requirement for EVOO classification. However, although no organoleptic defect could be perceived by the panelists for oils from lot \#1, confirming the EVOO classification; oils from lot \#2 had a winey-vinegary gustatory-retronasal negative sensation, which could be perceived with an average intensity greater than 3.5 , leading to a LOO quality classification, according to the EC recommendations (Commission Delegated Regulation [EU] 2015/1830, 2015).

The oils were split into 80 amber glass bottles $(125 \mathrm{~mL})$. Ten bottles from each quality grade (EVOO or LOO for lot $\# 1$ and \#2, respectively) were used as control, no flavoring agent being added $(2$ oil grades $\times 10$ bottle replicas $=20$ bottles). The other 60 olive oil bottles were flavored using two different flavoring agents (oregano-dried herbs and basil aromatic-dried herbs from a commercial brand, purchased from a local supermarket). For each flavoring agent (oregano or basil) and oil quality grade (EVOO or LOO, for lot \#1 and \#2, respectively), three concentration levels $(0.011,0.055$, and $0.110 \mathrm{~g}$ dried flavoring agent per $\mathrm{kg}$ olive oil) were studied, in quintuplicate resulting in a total of 60 bottles ( 3 levels $\times 2$ flavoring agents $\times 2$ oil grades $\times 5$ bottle replicas $=60$ bottles). All bottles were stored for 2 weeks in a dark environment, at room temperature $\left(18-25^{\circ} \mathrm{C}\right)$, before being analyzed.

\section{Evaluation of Olive Oils Quality Chemical Indices, OS, and Sensory Analysis}

The values of the free acidity (FA), extinction coefficients at 232 and $270 \mathrm{~nm}\left(K_{232}\right.$ and $\left.K_{270}\right)$, and peroxide value (PV) of the samples withdrawn from each of the 80 olive oil bottles, unflavored ( 20 bottles), or flavored (60 bottles) by incorporating different concentrations of oregano or basil dehydrated/dried leaves were determined according to the EC regulation (Commission Delegated Regulation [EU] 2015/1830, 2015). The oils OS was also assessed using the Rancimat method (Rodrigues et al., 2019). The oils sensory analysis was performed by the abovementioned panel, following the EC regulation (Commission Delegated Regulation [EU] 2015/1830, 2015), being specifically asked the assessment of the olfactory and gustatory-retronasal fruity positive attribute and of 
possible organoleptic defects, using an intensity scale ranging from 0 (absence of attribute) to 10 (maximum attribute intensity).

\section{E-tongue Analysis}

\section{E-Tongue Device and Setup}

A lab-made potentiometric multisensor E-tongue, comprising two cylindrical arrays, was used (Rodrigues et al., 2019). Each array contained 20 lipid polymeric crosssensitive sensor membranes (40 sensors in total), with a composition (lipid additive, 3\%; plasticizer, 32\%; and, polyvinyl chloride, $65 \%$ ) similar to that reported for the screen-printed E-tongues developed by the research team (Rodrigues et al., 2019; Veloso et al., 2016), although with greater diameter and thickness (greater contact surface), which allowed achieving more repeatable signal profiles and to minimize signal drifts (intraday coefficient of variation lower than 5\%) (Rodrigues et al., 2019). The sensor membranes were connected to a multiplexer Agilent Data Acquisition Switch Unit (model 34970A) controlled by the Agilent BenchLink Data Logger software installed on a PC. Each potentiometric assay took $5 \mathrm{~min}$ and allowed recording the potentiometric signals of the 40 sensor membranes generated through the establishment of electrostatic or hydrophobic interactions between the sensor membranes and polar compounds (Kobayashi et al., 2010). A reference $\mathrm{Ag} / \mathrm{AgCl}$ double-junction glass electrode (Crison, 5241) was used. The two sensor arrays were stored in a $\mathrm{HCl}$ solution $(0.01 \mathrm{M})$. The same sensor coding used in previous works was adopted: each sensor was identified with a letter $\mathrm{S}$ (for sensor) followed by the number of the array (1: or 2:) and the number of the membrane (1-20, corresponding to different combinations of plasticizers and additives).

\section{E-Tongue Analysis: Olive Oil Sample Preparation and Potentiometric Assays}

To overcome the difficulty of performing electrochemical assays in nonconductive and highly viscous liquids (Apetrei et al., 2010), olive oils (10 g) were extracted with $100 \mathrm{~mL}$ of hydroethanolic solution (80:20, water: ethanol, $\mathrm{v} / \mathrm{v})$. Also, these extracts are rich in polar compounds, including phenolic compounds, esters, alcohols, and aldehydes, which are responsible for several sensory positive and negative attributes (Veloso et al., 2016, 2018) and with which the lipid sensor membranes can interact through the establishment of electrostatic or hydrophobic interactions (Kobayashi et al., 2010). The mixture (olive oil plus hydroethanolic solution) was agitated for 1-2 min using a vortex stirrer (LBX V05 series, LBX Instruments,
LABBOX LABWARE S.L., Barcelona, Spain) at $500 \mathrm{rpm}$. Then, it was left at ambient temperature for $60 \mathrm{~min}$, after which, $60 \mathrm{~mL}$ of the supernatant solution was carefully withdrawn and immediately analyzed with the E-tongue, for a 5-min period, which allowed reaching a pseudoequilibrium between the lipid polymeric membranes of Etongue' and the chemical compounds of the extract. Electrochemical assays were performed in duplicate for each sample, with a third assay carried out if the potentiometric signal of any of the 40 sensors showed a coefficient of variation greater than $20 \%$ (value set according to EC regulations for sensory analysis). The E-tongue signals were normalized previously to any further statistical use.

\section{Statistical Analysis}

The influences of the type of flavoring agent used (basil or oregano) and of the concentration $(0,0.011,0.055$, and $0.110 \mathrm{~g}$ dried flavoring agent per kg olive oil) on the physicochemical parameters and sensory attributes of the unflavored or flavored olive oils were evaluated through the $t$-Student test or the one-way ANOVA, the significance of the interaction of "flavoring agent $\times$ concentration" being assessed by a two-way ANOVA. For the one-way ANOVA, the post-hoc multicomparison Tukey's test was further applied if a significant statistical effect was found ( $P$-value $<0.050)$. Besides, the $R$-Pearson correlation coefficients were also calculated to evaluate the existence of a linear trend between the OS or the intensity of sensory attributes and the added concentrations of each flavoring agent.

Linear discriminant analysis (LDA) coupled with the metaheuristic simulated annealing (SA) variable selection algorithm (Cadima et al., 2004) was used to evaluate the capability of the potentiometric E-tongue to simultaneously discriminate olive oils according to the oil quality grade (EVOO and LOO) and the deliberated oils flavoring/enrichment, or not, with aromatic herbs (oregano or basil). E-tongue-LDA-SA models were established based on the best subsets of the 40 normalized signal profiles generated during the electrochemical analysis, which were selected by the SA algorithm, aiming to minimize noise effects due to the inclusion of redundant potentiometric signals. The LDA predictive performance was assessed using the leave-one-out cross-validation (LOO-CV) technique taking into account the dimension of the independent dataset. The classification performance of each LDA model was also graphically evaluated using $2 \mathrm{D}$ or $3 \mathrm{D}$ plots of the main discriminant functions, the class membership boundary ellipses being determined based on the posterior probabilities computed using the Bayes' theorem (which enables controlling over-fitting issues) (Bishop, 2006). Finally, for each LDA model, the overall performance established was also assessed based on the sensitivity values, i.e., based on 
the percentage of correct classifications. All statistical analyses were performed using the open source statistical program R (version 2.15.1), at a 5\% significance level.

This article does not contain any studies with human participants or animals performed by any of the authors.

\section{Results and Discussion}

\section{Effect of Olive Oil Flavoring on the Physicochemical Quality Attributes, OS, and Fruity and Sensory Defect Intensities}

Unflavored and flavored olive oils (EVOO: lot \#1; and, LOO: lot \#2) were evaluated after 2 weeks of flavoring agent incorporation (or not) at three pre-established concentrations of the two dried aromatic herbs (basil or oregano). The values of the evaluated parameters (FA, PV, $K_{232}$, $K_{270}, \Delta K$, and OS) are given in Tables 1 and 2. The perceived intensities of fruity positive sensation and wineyvinegary negative attribute, assessed by the trained panelists, are also shown in Tables 1 and 2. A two-way ANOVA (data not shown) pointed out that, for both types of olive oils, and the evaluated physicochemical and sensory parameters, a significant interaction effect ("flavoring agent $\times$ concentration") was found ( $P$-value $\leq 0.01$ for the two-way ANOVA), with the exception of FA (EVOO: $P$-value $=0.1842), K_{232}($ EVOO: $P$-value $=0.1520)$, and $K_{270}$ (EVOO and LOO: $P$-value $\geq 0.4213$ ). Nevertheless, the significance of each individual effect ("flavoring agent" or "concentration") was further evaluated by the $t$-Student test or one-way ANOVA, respectively (Tables 1 and 2). The data showed that the physicochemical quality parameters of the EVOO and LOO studied were, in general, significantly influenced by the presence and concentration of each aromatic herb $(P$-value $<0.05$ for the one-way ANOVA). However, no clear trend could be established, an increase-decrease tendency being observed, depending on the olive oil quality, aromatic herb, and/or added concentration level. For the studied olive oils, the quality parameters changed and the extent of changes greatly depended on the starting olive oil grade and to a less extent on the flavoring agent and concentration used (Baiano et al., 2016). Gambacorta et al. (2007) reported that PV and $K_{232}$ values decreased with the addition of the flavoring agents (rosemary, hot pepper, oregano, and garlic) although no significant effect was observed for FA and $K_{270}$. Baiano et al. (2009) compared unflavored and flavored olive oils (with garlic, lemon, hot pepper, oregano, or rosemary) and found lower FA but higher values of PV, $K_{232}$, and $K_{270}$. However, Khemakhem et al. (2015) observed no changes between FA of flavored (sweet lime and sweet orange) and unflavored olive oils, although a significant increase of the PV values occurred for some flavored oils. Caponio et al. (2016) found that olive oils aromatized with spices had significantly higher levels of PV and $K_{232}$ compared to the unflavored oils. Other researchers reported an increase of FA values but not of the other quality indices (Ayadi et al., 2009; Sousa et al., 2015), while Caporaso et al. (2013) and Assami et al. (2016) observed a slight increase of all olive oil quality parameters with the addition of condiments. For example, Sacchi et al. (2017) verified a significant increase of FA, $K_{232}$, and $K_{270}$ values on olive oils flavored with lemon. Nevertheless, Clodoveo et al. (2016) did not found any differences using thyme or oregano. Benmoussa et al. (2016) found that flavoring olive oils with rosemary leaves leads to an increase of the FA, a decrease of PV and $K_{232}$, while no significant change was observed for $K_{270}$. The different effects reported in the literature (increase or decrease trends) or the absence of a significant influence on olive oils quality parameter levels and their oxidation stability, after the addition of natural flavoring agents, may be tentatively explained considering: the differences in chemical composition and bioactive contents of the aromatic plants/herbs or species used, the use of fresh or dried natural flavoring agents, and consequently the incorporation of water in the system, the different flavoring techniques as well as the specific olive oil characteristics (Clodoveo et al., 2016). It should be noticed that, in this work, the final levels of the physicochemical quality parameters of the unflavored and flavored olive oils remained below the legal thresholds established for EVOO classification (Commission Delegated Regulation [EU] 2015/1830, 2015).

This study also showed that OS significantly decreased with the increase of the flavoring agent concentration, being more pronounced for basil compared to oregano and for EVOO compared to LOO. However, other researchers reported an OS increase due to the addition of aromatic herbs or natural condiments (Assami et al., 2016; Gambacorta et al., 2007; Sousa et al., 2015), although this could depend on the flavoring agent (Ayadi et al., 2009; Issaoui et al., 2011). For example, a significant decrease of the OS was observed when dried chili pepper, hot pepper, lemon, rosemary, or sweet lime/orange were added to oils (Baiano et al., 2009; Caporaso et al., 2013; Khemakhem et al., 2015).

Finally, the major impact of the aromatizing process was at the olive oil sensory level. The fruity intensity of EVOO linearly increased with the increase of the flavoring concentration $(R$-Pearson $=+0.90$ and +0.94 for basil and oregano, respectively). A similar behavior was found for $\mathrm{LOO}$ (basil and oregano: $R$-Pearson $=+0.89$ and +0.92 , respectively). On the other hand, for EVOO, the addition of basil or oregano did not lead to the appearance of any sensory defect. Regarding LOO, the addition of basil or oregano 
Table 1 Physicochemical and sensory parameters of extra-virgin olive oils (lot \#1), 15 days after being flavored or not with dried aromatic herbs (basil or oregano at $0,0.011,0.055$, and $0.110 \mathrm{~g}$ per $\mathrm{kg}$ olive oil)

\begin{tabular}{|c|c|c|c|c|c|c|}
\hline \multirow[t]{2}{*}{ EVOO attribute (lot \#1) } & \multirow[t]{2}{*}{ Flavoring agent } & \multicolumn{5}{|c|}{ Concentration ( $\mathrm{g}$ dried oregano per kg olive oil) } \\
\hline & & $\begin{array}{c}0 \mathrm{~g} \mathrm{~kg}^{-1} \\
(10 \text { bottles })\end{array}$ & $\begin{array}{c}0.011 \mathrm{~g} \mathrm{~kg}^{-1} \\
(5 \text { bottles })\end{array}$ & $\begin{array}{c}0.055 \mathrm{~g} \mathrm{~kg}^{-1} \\
(5 \text { bottles })\end{array}$ & $\begin{array}{c}0.110 \mathrm{~g} \mathrm{~kg}^{-1} \\
(5 \text { bottles })\end{array}$ & $P$-value ${ }^{\mathrm{a}}$ \\
\hline \multicolumn{7}{|c|}{ Physicochemical parameters } \\
\hline \multirow[t]{3}{*}{ FA $(\%)$} & Basil & $0.17 \pm 0.01$ & $0.18 \pm 0.01$ & $0.17 \pm 0.00$ & $0.17 \pm 0.01$ & 0.6007 \\
\hline & Oregano & $0.17 \pm 0.01^{\mathrm{a}}$ & $0.15 \pm 0.01^{\mathrm{b}}$ & $0.16 \pm 0.01^{\mathrm{a}, \mathrm{b}}$ & $0.16 \pm 0.01^{\mathrm{a}, \mathrm{b}}$ & 0.0083 \\
\hline & $P$-value ${ }^{\mathrm{b}}$ & - & 0.0013 & 0.0246 & 0.3352 & \\
\hline \multirow[t]{3}{*}{$\mathrm{PV}\left(\mathrm{mEq} \mathrm{O} \mathrm{Kg}^{-1}\right)$} & Basil & $4.8 \pm 1.2$ & $4.4 \pm 0.2$ & $4.6 \pm 0.4$ & $5.2 \pm 0.5$ & 0.1458 \\
\hline & Oregano & $4.8 \pm 1.2^{\mathrm{a}}$ & $3.3 \pm 0.3^{\mathrm{b}}$ & $4.4 \pm 0.9^{\mathrm{a}, \mathrm{b}}$ & $5.6 \pm 1.4^{\mathrm{a}}$ & $<0.0001$ \\
\hline & $P$-value ${ }^{\mathrm{b}}$ & - & $<0.0001$ & 0.5773 & 0.4019 & \\
\hline \multirow[t]{3}{*}{$K_{232}$} & Basil & $1.507 \pm 0.043^{\mathrm{b}}$ & $2.073 \pm 0.044^{\mathrm{a}}$ & $2.042 \pm 0.055^{\mathrm{a}}$ & $2.024 \pm 0.077^{\mathrm{a}}$ & $<0.0001$ \\
\hline & Oregano & $1.507 \pm 0.043^{\mathrm{b}}$ & $2.053 \pm 0.080^{\mathrm{a}}$ & $2.107 \pm 0.074^{\mathrm{a}}$ & $2.034 \pm 0.085^{\mathrm{a}}$ & $<0.0001$ \\
\hline & $P$-value $^{\mathrm{b}}$ & - & 0.4896 & 0.0357 & 0.7882 & \\
\hline \multirow[t]{3}{*}{$K_{270}$} & Basil & $0.119 \pm 0.012^{b}$ & $0.138 \pm 0.009^{\mathrm{a}}$ & $0.136 \pm 0.003^{\mathrm{a}}$ & $0.139 \pm 0.004^{\mathrm{a}}$ & $<0.0001$ \\
\hline & Oregano & $0.119 \pm 0.012$ & $0.124 \pm 0.007$ & $0.119 \pm 0.015$ & $0.130 \pm 0.007$ & 0.0540 \\
\hline & $P$-value ${ }^{\mathrm{b}}$ & - & 0.0010 & 0.0019 & 0.0024 & \\
\hline \multirow[t]{3}{*}{ OS (h) } & Basil & $8.8 \pm 0.2^{\mathrm{a}}$ & $7.6 \pm 0.3^{b}$ & $7.6 \pm 0.2^{\mathrm{b}}$ & $7.6 \pm 0.2^{\mathrm{b}}$ & $<0.0001$ \\
\hline & Oregano & $8.8 \pm 0.2^{\mathrm{a}}$ & $8.4 \pm 0.2^{b}$ & $8.4 \pm 0.2^{\mathrm{b}}$ & $8.3 \pm 0.2^{b}$ & $<0.0001$ \\
\hline & $P$-value ${ }^{\mathrm{b}}$ & - & $<0.0001$ & $<0.0001$ & $<0.0001$ & \\
\hline \multicolumn{7}{|c|}{ Sensory analysis (intensity, $0-10$ scale, 0 : sensation not perceived to 10 : maximum perceived intensity) } \\
\hline \multirow[t]{3}{*}{ Fruity sensation } & Basil & $3.9 \pm 0.4^{\mathrm{d}}$ & $5.3 \pm 0.3^{\mathrm{c}}$ & $6.0 \pm 0.3^{\mathrm{b}}$ & $6.7 \pm 0.3^{\mathrm{a}}$ & $<0.0001$ \\
\hline & Oregano & $3.9 \pm 0.4^{\mathrm{d}}$ & $5.3 \pm 0.2^{\mathrm{c}}$ & $6.4 \pm 0.2^{\mathrm{b}}$ & $7.4 \pm 0.3^{\mathrm{a}}$ & $<0.0001$ \\
\hline & $P$-value & - & 0.7974 & 0.0064 & $<0.0001$ & \\
\hline \multirow[t]{2}{*}{ Defect sensation } & Basil & N.D. & N.D. & N.D. & N.D. & \\
\hline & Oregano & N.D. & N.D. & N.D. & N.D. & \\
\hline
\end{tabular}

FA, free acidity; $K_{232}$ and $K_{270}$, extinction coefficients at 232 and $270 \mathrm{~nm}$, respectively; N.D., not detected (no sensations perceived by the trained panelists); OS, oxidative stability; PV, peroxide values.

${ }^{a}$ For each line, a $P$-value $<0.05$ (bold and italic) means that for each flavoring agent (basil or oregano), the mean value of the evaluated parameter of at least one aromatizing concentration differs from the others, according to the one-way ANOVA. In each line, different small letters mean significant statistical differences of the parameter under evaluation, at a 5\% significance level, according to multiple comparison Tukey's HSD test.

${ }^{\mathrm{b}}$ For each column and for aromatizing concentration level, a $P$-value $<0.05$ (bold and italic) means that the mean value of the evaluated parameter varied significantly with the type of flavoring agent, according to $t$-Student test.

contributed to mask the sensory defect (winey-vinegary negative attribute) intensity, which linearly decreased with the increase of the flavoring concentration (basil and oregano: $R$-Pearson $=-0.95$ and -0.99 , respectively). It should be remarked that the olive oil aromatization, with the highest oregano concentration $(0.110 \mathrm{~g}$ dried oregano per $\mathrm{kg}$ olive oil) could mask the intensity of the perceived defect to such an extent that the initial LOO classification could be changed to VOO. This fact is of major relevance, pointing out the possibility of using flavoring agents for masking olive oil sensory negative attributes allowing the fraudulent commercialization of LOO as aromatized VOO. Although the defect intensity decrease was not so sharp for LOO flavored with basil, the final value achieved (defect mean intensity: $3.8 \pm 0.3$ ) also opens the possibility of using this flavoring agent at a higher concentration level to mask the presence and intensity of negative organoleptic attributes. Therefore, the development of fast, user-friendly, and cost-effective analytical tools that could unmask lowquality olive oils flavored with aromatic herbs is a real need and can play an important role as a quality control tool. In this context, the use of a potentiometric E-tongue as a taste sensor quality device was evaluated for the first time to the authors' best knowledge.

\section{E-Tongue Analysis of Flavored and Unflavored Olive Oils}

\section{Basil Flavoring Process}

The results of the sensory analysis (Table 2) showed that flavoring LOO with basil allowed masking the intensity of 
Table 2 Physicochemical and sensory parameters of lampante olive oils (lot \#2), 15 days after being flavored or not with dried aromatic herbs (basil or oregano at $0,0.011,0.055$, and $0.110 \mathrm{~g} \mathrm{~kg}^{-1}$ olive oil)

\begin{tabular}{|c|c|c|c|c|c|c|}
\hline \multirow[t]{2}{*}{ LOO attribute (lot \#2) } & \multirow[t]{2}{*}{ Flavoring agent } & \multicolumn{5}{|c|}{ Concentration ( $\mathrm{g}$ dried oregano per kg olive oil) } \\
\hline & & $\begin{array}{c}0 \mathrm{~g} \mathrm{~kg}^{-1} \\
(10 \text { bottles })\end{array}$ & $\begin{array}{l}0.011 \mathrm{~g} \mathrm{~kg}^{-1} \\
\text { (5 bottles) }\end{array}$ & $\begin{array}{c}0.055 \mathrm{~g} \mathrm{~kg}^{-1} \\
(5 \text { bottles })\end{array}$ & $\begin{array}{c}0.110 \mathrm{~g} \mathrm{~kg}^{-1} \\
(5 \text { bottles })\end{array}$ & $P$-value ${ }^{\mathrm{a}}$ \\
\hline \multicolumn{7}{|c|}{ Physicochemical parameters } \\
\hline \multirow[t]{3}{*}{ FA $(\%)$} & Basil & $0.25 \pm 0.01^{\mathrm{a}, \mathrm{b}}$ & $0.26 \pm 0.01^{\mathrm{a}}$ & $0.26 \pm 0.02^{\mathrm{a}}$ & $0.24 \pm 0.02^{\mathrm{b}}$ & 0.0104 \\
\hline & Oregano & $0.25 \pm 0.01^{\mathrm{b}}$ & $0.27 \pm 0.02^{\mathrm{a}}$ & $0.27 \pm 0.02^{\mathrm{a}}$ & $0.28 \pm 0.02^{\mathrm{a}}$ & $<0.0001$ \\
\hline & $P$-value ${ }^{\mathrm{b}}$ & - & 0.0538 & 0.1783 & 0.0001 & \\
\hline \multirow[t]{3}{*}{$\mathrm{PV}\left(\mathrm{mEq} \mathrm{O} \mathrm{Og}^{-1}\right)$} & Basil & $8.4 \pm 1.0$ & $8.5 \pm 0.8$ & $7.8 \pm 0.4$ & $8.6 \pm 0.6$ & 0.1529 \\
\hline & Oregano & $8.4 \pm 1.0^{\mathrm{a}}$ & $8.9 \pm 1.6^{\mathrm{a}}$ & $7.9 \pm 1.0^{\mathrm{a}, \mathrm{b}}$ & $7.1 \pm 0.3^{\mathrm{b}}$ & 0.0025 \\
\hline & $P$-value ${ }^{\mathrm{b}}$ & - & 0.5299 & 0.7536 & $<0.0001$ & \\
\hline \multirow[t]{3}{*}{$K_{232}$} & Basil & $2.127 \pm 0.070^{\mathrm{a}}$ & $2.161 \pm 0.055^{\mathrm{a}}$ & $1.925 \pm 0.025^{\mathrm{b}}$ & $2.156 \pm 0.043^{\mathrm{a}}$ & $<0.0001$ \\
\hline & Oregano & $2.127 \pm 0.070^{\mathrm{a}}$ & $2.056 \pm 0.108^{\mathrm{a}, \mathrm{b}}$ & $2.024 \pm 0.115^{\mathrm{b}}$ & $2.026 \pm 0.103^{\mathrm{b}}$ & 0.0132 \\
\hline & $P$-value ${ }^{\mathrm{b}}$ & - & 0.0137 & 0.0160 & 0.0017 & \\
\hline \multirow[t]{3}{*}{$K_{270}$} & Basil & $0.126 \pm 0.008^{\mathrm{b}}$ & $0.141 \pm 0.008^{\mathrm{a}}$ & $0.139 \pm 0.006^{\mathrm{a}}$ & $0.127 \pm 0.004^{\mathrm{b}}$ & $<0.0001$ \\
\hline & Oregano & $0.126 \pm 0.008^{\mathrm{b}}$ & $0.138 \pm 0.013^{\mathrm{a}}$ & $0.132 \pm 0.014^{\mathrm{a}, \mathrm{b}}$ & $0.120 \pm 0.013^{\mathrm{b}}$ & 0.0053 \\
\hline & $P$-value ${ }^{\mathrm{b}}$ & - & 0.5734 & 0.1406 & 0.1372 & \\
\hline \multirow[t]{3}{*}{ OS (h) } & Basil & $6.8 \pm 0.2^{\mathrm{a}}$ & $6.0 \pm 0.1^{\mathrm{b}}$ & $6.0 \pm 0.3^{\mathrm{b}}$ & $6.0 \pm 0.1^{\mathrm{b}}$ & $<0.0001$ \\
\hline & Oregano & $6.8 \pm 0.2^{\mathrm{a}}$ & $6.3 \pm 0.2^{b}$ & $6.4 \pm 0.1^{\mathrm{b}}$ & $6.3 \pm 0.1^{\mathrm{b}}$ & $<0.0001$ \\
\hline & $P$-value ${ }^{\mathrm{b}}$ & - & 0.0004 & 0.0005 & $<0.0001$ & \\
\hline \multicolumn{7}{|c|}{ Sensory analysis (intensity, $0-10$ scale, 0 : sensation not perceived to 10 : maximum perceived intensity) } \\
\hline \multirow[t]{3}{*}{ Fruity sensation } & Basil & $1.7 \pm 0.3^{\mathrm{d}}$ & $2.7 \pm 0.1^{\mathrm{c}}$ & $3.1 \pm 0.2^{\mathrm{b}}$ & $3.6 \pm 0.3^{\mathrm{a}}$ & $<0.0001$ \\
\hline & Oregano & $1.7 \pm 0.3^{\mathrm{c}}$ & $2.2 \pm 0.2^{\mathrm{b}}$ & $3.6 \pm 0.4^{\mathrm{a}}$ & $3.8 \pm 0.3^{\mathrm{a}}$ & $<0.0001$ \\
\hline & $P$-value ${ }^{\mathrm{b}}$ & - & $<0.0001$ & 0.0090 & 0.2205 & \\
\hline \multirow[t]{3}{*}{ Defect sensation } & Basil & $5.9 \pm 0.4^{\mathrm{d}}$ & $5.1 \pm 0.4^{\mathrm{c}}$ & $4.5 \pm 0.4^{b}$ & $3.8 \pm 0.3^{\mathrm{a}}$ & $<0.0001$ \\
\hline & Oregano & $5.9 \pm 0.4^{\mathrm{d}}$ & $5.1 \pm 0.6^{\mathrm{c}}$ & $3.8 \pm 0.3^{b}$ & $2.2 \pm 0.3^{\mathrm{a}}$ & $<0.0001$ \\
\hline & $P$-value ${ }^{\mathrm{b}}$ & - & 0.9675 & 0.0003 & $<0.0001$ & \\
\hline
\end{tabular}

FA, free acidity; $K_{232}$ and $K_{270}$, extinction coefficients at 232 and $270 \mathrm{~nm}$, respectively; N.D., not detected (no sensations perceived by the trained panelists); OS, oxidative stability; PV, peroxide values.

${ }^{a}$ For each line, a $P$-value $<0.05$ (bold and italic) means that for each flavoring agent (basil or oregano), the mean value of the evaluated parameter of at least one aromatizing concentration differs from the others, according to the one-way ANOVA. In each line, different small letters mean significant statistical differences of the parameter under evaluation, at a 5\% significance level, according to multiple comparison Tukey's HSD test.

${ }^{\mathrm{b}}$ For each column and for aromatizing concentration level, a $P$-value $<0.05$ (bold and italic) means that the mean value of the evaluated parameter varied significantly with the type of flavoring agent, according to $t$-Student test.

the winey-vinegary defect. Indeed, the panelists' perceived intensities significantly decreased with the increasing basil concentration (from an average intensity of $5.9 \pm 0.4$, for unflavored LOO, to $3.8 \pm 0.3$ for the LOO aromatized with the maximum basil concentration). In fact, the addition of basil to LOO allowed masking the sensory defect perception and for the highest concentration evaluated, the flavored oil almost reached a defect intensity that could allow its fraudulent classification as En-VOO (a classification of VOO requires that any sensory defect could only be perceived at a maximum intensity $\leq 3.5$ ). In this context, the potentiometric signals of the 40 sensor E-tongue membranes recorded during the analysis of the flavored and unflavored olive oil samples (EVOO; LOO; EVOO enriched with basil: EVOO-basil; and, LOO enriched with basil: LOO-basil) were used, after normalization, to establish multivariate supervised classification models. The best subset of sensors was selected by applying the metaheuristic SA algorithm, based on the predictive classification performance (LOO-CV procedure). An E-tongueLDA-SA model was established (three linear discriminant [LD] functions explaining 74.5, 14.7, and $10.8 \%$ of the original data variability). The model used the normalized potentiometric data collected from 20 sensors (1st array: $\mathrm{S} 1: 3, \mathrm{~S} 1: 4, \mathrm{~S} 1: 6, \mathrm{~S} 1: 7, \mathrm{~S} 1: 8, \mathrm{~S} 1: 10, \mathrm{~S} 1: 12$, and S1:14-S1:20; 2nd array: S2:5, S2:9, S2:12, S2:13, S2:16, and S2:19) during analysis of the hydroethanolic extracts of olive oils. The multivariate supervised classification model allowed correctly classifying $94 \%$ of the original grouped samples (Fig. 1) and correctly classify $70 \%$ of the 
samples (LOO-CV). It should be remarked that the misclassifications were observed for all groups with the exception of LOO samples, which were all correctly classified. The predicted classification performance was satisfactory taking into account the complexity of this challenging task. Actually, all unflavored oils evaluated (lots \#1 and \#2) could be classified as EVOO from a physicochemical point of view, fulfilling the legal thresholds required for this classification (Commission Delegated Regulation [EU] 2015/1830, 2015). Moreover, the basil aromatization was performed at three different concentration levels (ranging from 0.011 to $0.110 \mathrm{~g}$ dried basil per kg olive oil). The reduced olive oil aromatizing time and the low flavoring levels assessed may pose additional practical difficulties. Therefore, the capability of the E-tongue to identify LOO-basil samples and differentiate them from EVOO, LOO, and EVOO-basil samples is of utmost commercial importance.

Furthermore, the use of the E-tongue for differentiating the flavored EVOO or flavored LOO according to the three different added basil concentration levels was further investigated. For EVOO-basil and LOO-basil, it was possible to establish E-tongue-LDA-SA models with two discriminant functions (that explained $100 \%$ of the original data variability), based on the normalized signals of six sensors (1st array: S1:16, and S1:18; 2nd array: S2:2, S2:3, S2:11, and S2:20) and seven sensors (1st array: S1:5, S1:12, and $\mathrm{S} 1: 19 ;$ 2nd array: S2:3, S2:11, S2:18, and S2:20), respectively. The models allowed $100 \%$ of correct classifications for the original grouped samples (Fig. 1) and 93\% for the LOO-CV procedure. The results showed that the E-tongue was able to detect and discriminate the different levels of basil flavored oils, confirming its potential as a taste sensor device for olive oil analysis.

\section{Oregano Flavoring Process}

Multivariate supervised classification models were established for the evaluation of oregano flavored and unflavored olive oils (EVOO; LOO; EVOO enriched with oregano: EVOO-oregano; and LOO enriched with basil: LOO-oregano). In this case, a subset of 17 sensors (1st array: S1:7, S1:9, S1:11-S1:13, S1:15, and S1:16; 2nd array: S2:4-S2:6, S2:9, S2:11, S2:12, S2:14-S2:16, and $\mathrm{S} 2: 19)$ was selected using the SA algorithm and further used to establish the E-tongue-LDA-SA model

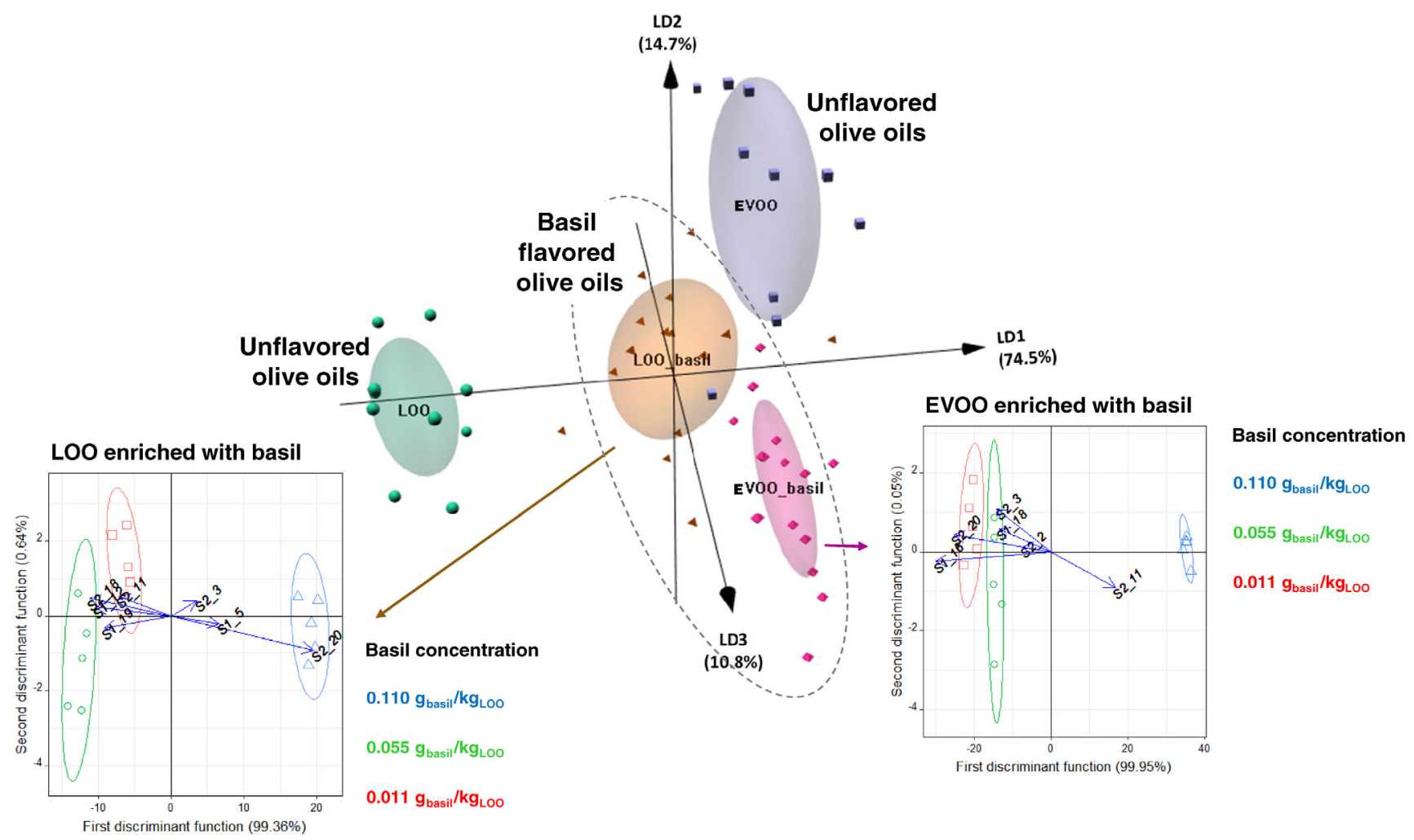

Fig. 1 Discrimination of unflavored and flavored olive oils according to the grade quality (EVOO and LOO) and the level of added flavoring agent (basil-dried herb): E-tongue-LDA-SA models established based on the E-tongue potentiometric signals gathered by the lipid polymeric sensor membranes during the analysis of hydroethanolic extracts of olive oils 


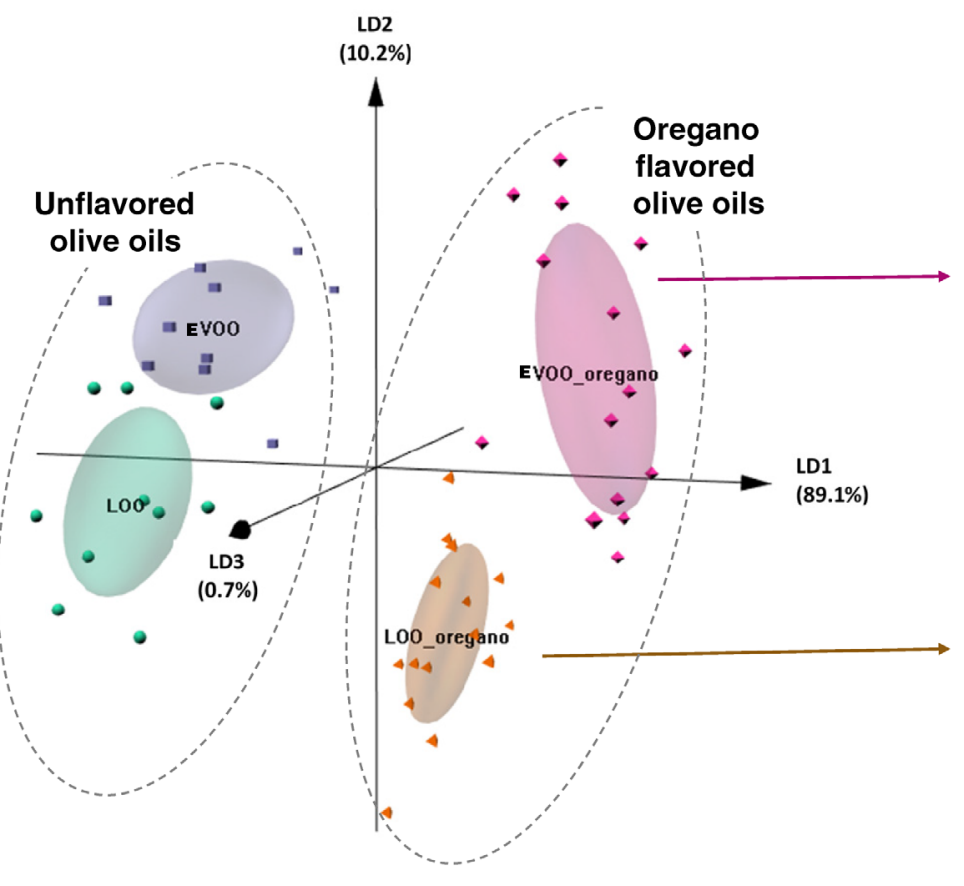

EVOO enriched with oregano
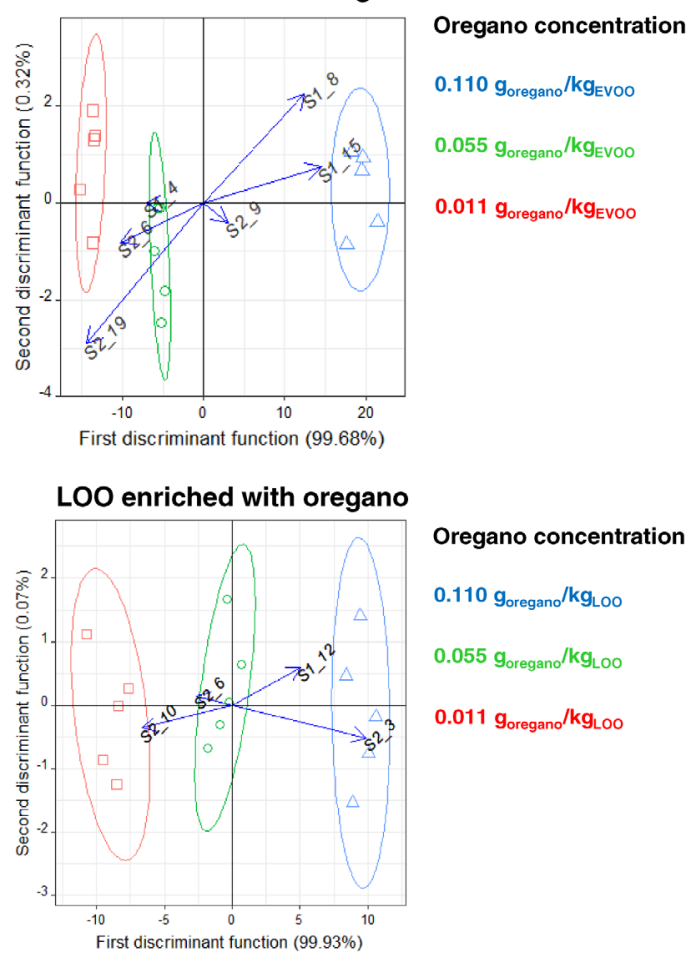

Fig. 2 Discrimination of unflavored and flavored olive oils according to the grade quality (EVOO and LOO) and the level of added flavoring agent (oregano-dried herb): E-tongue-LDA-SA models established based on the E-tongue potentiometric signals gathered by the lipid polymeric sensor membranes during the analysis of hydroethanolic extracts of olive oils

(LD explaining $89.1 \%, 10.2 \%$, and $0.7 \%$ of the original data variability). The selected classification model showed sensitivities of $98 \%$ for the original grouped samples (Fig. 2) and $78 \%$ for the LOO-CV procedure. The slightly better predictive performance achieved (compared to that of the basil flavoring process) may be tentatively attributed to the higher influence of the oregano enrichment on the olive oils' physicochemical and sensory levels. It should be remarked that olive oils flavored with oregano showed lowest misclassification ratios, and so, at the studied flavoring levels, oregano seems to be a more potent/intense flavoring agent than basil. The increasing addition of oregano leads to a higher decrease of perception of the winey-vinegary defect (in comparison to the basil addition) leading to a minimum perceived average intensity of $2.2 \pm 0.3$ for the highest oregano concentration (Table 2). The defect masking potential of oregano would allow an erroneous classification, by the trained panelists, of the LOO with $0.1100 \mathrm{~g} \mathrm{~kg}^{-1}$ as an enriched VOO. However, the E-tongue enabled the correct classification of 12 of the 15 LOOoregano samples (predictive sensitivity of $80 \%$ for the LOO-CV procedure), demonstrating that it could be a practical complementary tool for the sensory analysis of flavored oils. The models allowed the correct classifications of $100 \%$ of the flavored oils for the original grouped samples (Fig. 2) as well as for the LOO-CV procedure. Once again, these results demonstrate the feasibility of using the E-tongue for olive oil analysis, specifically for their complex sensory evaluation.

\section{Conclusions}

The study carried out allowed concluding that olive oil flavoring with basil or oregano slightly influences the quality of physicochemical parameters but mainly their OS (which was reduced compared to the unflavored oils) and their sensory attributes (with an increase of the fruity positive sensation and a significant decrease of the wineyvinegary negative intensity), leading to a possible classification of a flavored lampante oil as a flavored virgin oil. This work also demonstrated that a potentiometric Etongue, comprising lipid sensor membranes, can be efficiently used to unmask the presence of the winey-vinegary negative sensation in flavored olive oils, which have been enriched by the addition of different basil or oregano concentrations. The proposed electrochemical-chemometric 
approach showed to be a practical and accurate taste-sensor device that could be used as a complementary tool for olive oil sensory analysis. The satisfactory results pointed out that the E-tongue is a powerful screening procedure, implementation of which can be foreseen in a near future, if one can overcome the usual skepticism of the industrial partners regarding this novel sensor-based devices.

Acknowledgments This work was financially supported by Associate Laboratory LSRE-LCM-UID/EQU/50020/2019, strategic funding UID/BIO/04469/2019-CEB, BioTecNorte operation (NORTE-01-0145-FEDER-000004), and strategic project PEstOE/AGR/UI0690/2014 - CIMO, funded by national funds through FCT/MCTES (PIDDAC).

Conflict of Interest The authors declare that they have no conflict of interest.

\section{References}

Apetrei, C., Apetrei, I. M., Villanueva, S., de Saja, J. A., GutierrezRosales, F., \& Rodriguez-Mendez, M. L. (2010) Combination of an e-nose, an e-tongue and an e-eye for the characterisation of olive oils with different degree of bitterness. Analytica Chimica Acta, 663:91-97. https://doi.org/10.1016/j.aca.2010.01.034

Assami, K., Chemat, S., Meklati, B. Y., \& Chemat, F. (2016) Ultrasound-assisted aromatisation with condiments as an enabling technique for olive oil flavouring and shelf life enhancement. Food Analytical Methods, 9:982-990. https://doi.org/10.1007/s12161015-0273-9

Ayadi, M. A., Grati-Kamoun, N., \& Attia, H. (2009) Physico-chemical change and heat stability of extra virgin olive oils flavoured by selected Tunisian aromatic plants. Food and Chemical Toxicology, 47:2613-2619. https://doi.org/10.1016/j.fct.2009.07.024

Baiano, A., Previtali, M. A., Viggiani, I., Varva, G., Squeo, G., Paradiso, V. M., ... Caponio, F. (2016) As oil blending affects physical, chemical, and sensory characteristics of flavoured olive oils. European Food Research and Technology, 242:1693-1708. https://doi.org/10.1007/s00217-016-2669-1

Baiano, A., Terracone, C., Gambacorta, G., \& La Notte, E. (2009) Changes in quality indices, phenolic content and antioxidant activity of flavored olive oils during storage. Journal of the American Oil Chemists' Society, 86:1083-1092. https://doi.org/10.1007/ s11746-009-1446-8

Benmoussa, H., Elfalleh, W., Farhat, A., Servili, M., Algabr, M., \& Romdhane, M. (2016) Impact of microwave assisted infusion on the quality and volatile composition of olive oil aromatized with rosemary leaves. Journal of the American Oil Chemists' Society, 93:921-928. https://doi.org/10.1007/s11746-016-2847-0

Bishop, C. M. (2006) Pattern recognition and machine learning (1st ed.). New York, NY: Springer.

Cadima, J., Cerdeira, J. O., \& Minhoto, M. (2004) Computational aspects of algorithms for variable selection in the context of principal components. Computational Statistics \& Data Analysis, 47: 225-236. https://doi.org/10.1016/j.csda.2003.11.001

Caponio, F., Durante, V., Varva, G., Silletti, R., Previtali, M. A., Viggiani, I., ... Baiano, A. (2016) Effect of infusion of spices into the oil vs. combined malaxation of olive paste and spices on quality of naturally flavoured virgin olive oils. Food Chemistry, 202: 221-228. https://doi.org/10.1016/j.foodchem.2016.02.005

Caporaso, N., Paduano, A., Nicoletti, G., \& Sacchi, R. (2013) Capsaicinoids, antioxidant activity, and volatile compounds in olive oil flavored with dried chili pepper (Capsicum annuum). European Journal of Lipid Science and Technology, 115:1434-1442. https:// doi.org/10.1002/ejlt.201300158

Clodoveo, M. L., Dipalmo, T., Crupi, P., Durante, V., Pesce, V., Maiellaro, I., ... Franchini, C. (2016) Comparison between different flavored olive oil production techniques: Healthy value and process efficiency. Plant Foods for Human Nutrition, 71:81-87. https://doi.org/10.1007/s11130-016-0528-7

Commission Delegated Regulation (EU) 2015/1830 (2015) Commission Delegated Regulation (EU) 2015/1830 of 8 July 2015 amending Regulation (EEC) No 2568/91 on the characteristics of olive oil and olive-residue oil and on the relevant methods of analysis. Official Journal of the European Union, L266:9-13.

Gambacorta, G., Faccia, M., Pati, S., Lamacchia, C., Baiano, A., \& La Notte, E. (2007) Changes in the chemical and sensorial profile of extra virgin olive oils flavored with herbs and spices during storage. Journal of Food Lipids, 14:202-215. https://doi.org/10.1111/j. 1745-4522.2007.00080.x

Harzalli, U., Rodrigues, N., Veloso, A. C. A., Dias, L. G., Pereira, J. A., Oueslati, S., \& Peres, A. M. (2018) A taste sensor device for unmasking admixing of rancid or winey-vinegary olive oil to extra virgin olive oil. Computers and Electronics in Agriculture, 144:222-231. https://doi.org/10.1016/j.compag.2017.12.016

Issaoui, M., Flamini, G., Hajaij, M. E., Cioni, P. L., \& Hammami, M. (2011) Oxidative evolution of virgin and flavored olive oils under thermo-oxidation processes. Journal of the American Oil Chemists' Society, 88:1339-1350. https://doi.org/10.1007/s11746-011-1800-5

Khemakhem, I., Yaiche, C., Ayadi, M. A., \& Bouaziz, M. (2015) Impact of aromatization by Citrus limetta and Citrus sinensis peels on olive oil quality, chemical composition and heat stability. Journal of the American Oil Chemists' Society, 92:701-708. https://doi. org/10.1007/s11746-015-2636-1

Kobayashi, Y., Habara, M., Ikezazki, H., Chen, R., Naito, Y., \& Toko, K. (2010) Advanced taste sensors based on artificial lipids with global selectivity to basic taste qualities and high correlation to sensory scores. Sensors, 10:3411-3443. https://doi.org/10.3390/ s100403411

Moldão-Martins, M., Beirão-da-Costa, S., Neves, C., Cavaleiro, C., Salgueiro, L., \& Beirão-da-Costa, M. L. (2004) Olive oil flavoured by the essential oils of Mentha $\times$ piperita and Thymus mastichina L. Food Quality and Preference, 15:447-452. https://doi.org/10. 1016/j.foodqual.2003.08.001

Rodrigues, N., Marx, Í. M. G., Casal, S., Dias, L. G., Veloso, A. C. A., Pereira, J. A., \& Peres, A. M. (2019) Application of an electronic tongue as a single-run tool for olive oils' physicochemical and sensory simultaneous assessment. Talanta, 197: 363-373. https://doi.org/10.1016/j.talanta.2019.01.055

Rubió, L., Motilva, M.-J., Macià, A., Ramo, T., \& Romero, M.-P. (2012) Development of a phenol-enriched olive oil with both its own phenolic compounds and complementary phenols from thyme. Journal of Agricultural and Food Chemistry, 60:3105-3112. https://doi.org/10.1021/jf204902w

Sacchi, R., Medaglia, D. D., Paduano, A., Caporaso, N., \& Genovese, A. (2017) Characterisation of lemon-flavoured olive oils. LWT-Food Science and Technology, 79:326-332. https://doi. org/10.1016/j.lwt.2017.01.025

Sinelli, N., Cerretani, L., Egidio, V. D., Bendini, A., \& Casiraghi, E. (2010) Application of near (NIR) infrared and mid (MIR) infrared spectroscopy as a rapid tool to classify extra virgin olive oil on the basis of fruity attribute intensity. Food Research International, 43: 369-375. https://doi.org/10.1016/j.foodres.2009.10.008

Sousa, A., Casal, S., Malheiro, R., Lamas, H., Bento, A., \& Pereira, J. A. (2015) Aromatized olive oils: Influence of flavouring in quality, composition, stability, antioxidants, and antiradical potential. LWT_Food Science and Technology, 60:22-28. https:// doi.org/10.1016/j.lwt.2014.08.026 
Veloso, A. C. A., Dias, L. G., Rodrigues, N., Pereira, J. A., \& Peres, A. M. (2016) Sensory intensity assessment of olive oils using an electronic tongue. Talanta, 146:585-593. https://doi.org/10. 1016/j.talanta.2015.08.071
Veloso, A. C. A., Silva, L. M., Rodrigues, N., Rebello, L. P. G., Dias, L. G., Pereira, J. A., \& Peres, A. M. (2018) Perception of olive oils sensory defects using a potentiometric taste device. Talanta, 176:610-618. https://doi.org/10.1016/j.talanta.2017.08.066 